\title{
The survey about live broadcast teaching in Chinese middle schools during the COVID-19 Pandemic
}

\author{
Liang Yu' ${ }^{1} \cdot$ Mingxiang Lan $^{1} \cdot$ Menghang Xie ${ }^{1}$
}

Received: 24 January 2021 / Accepted: 25 May 2021/Published online: 5 June 2021

(C) The Author(s), under exclusive licence to Springer Science+Business Media, LLC, part of Springer Nature 2021

\begin{abstract}
With the rapid advancement of China's "Internet plus Education" plan, "Internet plus Education" has become a research hotspot. The outbreak of COVID-19 pandemic has brought great opportunities, tests and inspections for online education. All schools earnestly implemented the relevant requirements of the Ministry of Education and leverage the strengths of the Internet to ensure that "suspension of classes and non-stop teaching". Taking a middle school in the west part of China as an example, the online survey was conducted to investigate its live broadcast teaching. The independent sample test and one-way analysis of variance were used to statistically analyze the differences among the students' genders, grades, home location, type of device used and parental companionship. Finally, the implications were put forward to provide a reference for live teaching practice.
\end{abstract}

Keywords COVID-19 pandemic · Live broadcast teaching · Teaching model · Satisfaction

\section{Introduction}

With the continuous progress of Internet technology, the rapid development of online education represented by MOOC has brought new changes, new opportunities and new vitality to education. Online learning platforms have mushroomed because of the popularity of their time-free convenience. However, studies have shown that in this kind of recording and broadcasting teaching, the interaction

Liang Yu

yuliang@swu.edu.cn

Mingxiang Lan

1366192301@qq.com

Menghang Xie

616365382@qq.com

1 Faculty of Education, Southwest University, Chongqing 400715, P. R. China 
between teachers and students is limited, and the course satisfaction is relatively low (Moridani, 2007). In 2016, live broadcasting entered the public's vision. Due to its real-time, convenience, interactivity and other features favored by the capital market, the model of live broadcast teaching has also become popular, bringing new opportunities and challenges for online education (Cheng et al., 2020; Liu, 2017). Live broadcast teaching can provide real-time communication between teachers and students, instant response for students' questions, and savings in terms of time and cost (Salmon, 2000). Many studies have addressed on the tools and devices used in live broadcast teaching and their effect on the learning performance (Murphy \& Laferriére, 2007; Park \& Bonk, 2007; Teng et al., 2012; Richardson, 2020). Other research has investigated the effect of learner-learner and learner-instructor interactions on students' satisfaction (Halverson et al., 2014; Kuo et al., 2014; Ng, 2007). Martin et al. (2017) highlighted that demographics are very important for research in the ability to discern what interventions are effective for whom (age, gender, etc.) and under what conditions. Among demographic variables, gender and age were investigated by most research related to live broadcast teaching (Martin et al., 2017).

At the end of 2019, the COVID-19 appeared in Wuhan, Hubei province and quickly spread across the country (Hui et al., 2020). In order to prevent the COVID19 from spreading on campus, the Ministry of Education has requested that the spring semester in 2020 be postponed and required schools to attach great importance to preparation in the work of "Suspension of classes and non-stop teaching ", and improve online education and teaching (Ministry of Education, PRC, 2020a, 2020b). The COVID-19 pandemic has brought great opportunities and great tests to online education, especially live broadcast teaching. The country has also placed great hopes on online education and endowed online education with a new historical mission.

Live broadcast teaching during the COVID-19 pandemic is different from the general synchronous online learning. The COVID-19 pandemic made traditional classroom teaching directly switch to online teaching. Teachers and students have no choice but to adapt passively to this teaching method. under these situations, teachers may fall back on copy familiar face-to-face practices to live broadcast teaching.

There is little research focus on satisfaction, matters needing attention, coping strategies, learners' demographic differences (e.g. age, gender) and other aspects of live broadcast teaching, especially lack of such large-scale, multi-disciplinary and full-line live broadcast teaching research. This study was to investigate students' satisfaction with live broadcast teaching, analyze the demographic differences between learners under different conditions of live broadcast teaching, find problems in live broadcast teaching, provide reference for practice of live broadcast teaching.

\section{The implementation model of live broadcast teaching}

Teachers conduct live teaching for students with the help of relevant live broadcasting software. Live broadcast teaching model generally consists of three parts: (a) before class, teachers issue preview tasks, and students preview independently; (b) in class, teachers explain the knowledge points and interact with students on difficult 
problems in real time; (c) after class, students review and consolidate knowledge they have learned. Chen et al. (2005) built an online synchronous learning model with five dimensions: role (teacher, student), participant (individual, group), venue (specific, any), interaction (one-way, two-way) and delivery (playback, live).

Due to the special situation of the COVID-19 pandemic, the number of students in live broadcast teaching is much higher. Meanwhile, schools have to earnestly implement the relevant requirements of the Ministry of Education and the higher authorities. Therefore, the schools make full use of the live teaching platform required by the superior and specially developed in their region and fully combines with schools' ICT equipment. We built the live broadcast teaching model during the COVID-19 pandemic based on these circumstances, as shown in Fig. 1.

It includes pre-class, in-class and after-class teaching activities. The core of live broadcast teaching model is in-class live broadcast teaching and after-class questionanswering. Before class, the teacher has a discussion with the teaching and research team. Then the teacher needs to complete the teaching plan and the design of live broadcast teaching, informs students in advance of the course learning arrangement together with the teachers of each class, and requires the students to conscientiously complete the guided study plan and preview task. In the class, the teacher conducts live broadcast teaching, and students join the class at home.

The teacher explains the course content as planned and writes on the blackboard, which attracts students' attention through appropriate questions, reminders and other hidden interactive ways. During or after the explanation, the teacher will show the corresponding exercises to the students, leave a little time for them to think and finish the exercises, and then make some comments. Finally, the teacher summarizes the key and difficult points of the lecture, and assigns homework to students. In class, students mainly watch the live broadcast to learn relevant knowledge points, make notes, and cooperate with the live broadcast teacher to conduct corresponding invisible interaction. After class, students' acquired knowledge will be consolidated by homework. Students finish the homework carefully within the specified time as required. After the completion of homework, teachers should release the homework answers through information tools within a certain time. After that, students

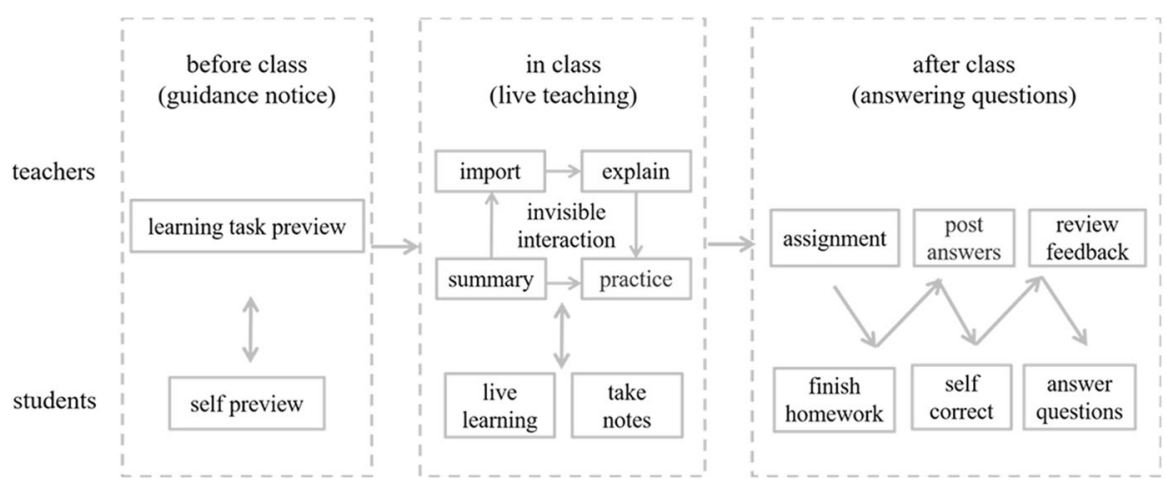

Fig. 1 Live broadcast teaching model 
independently correct the answers according to the answers released by teachers and upload them to the Internet through the corresponding tools. Finally, the teacher will focus on the explanation of difficult questions through different social software such as QQ group, WeChat group and DingTalk group.

\section{Method}

\subsection{Participants and procedure}

The survey was conducted at a middle school in western part of China between June 1 and July 1, 2020. All participants were recruited by the teacher who in charge of class and informed of the purpose of this study, the requirements of participation, and how the information collected from them will be used without revealing their personal information. The students would be approved to join the survey after they submitted their parents' consent paper. This sample consisted of 1336 females (47\%) and 1492 males (53\%), and 879 (31\%) students from grade one, $1016(36 \%)$ students from grade two, and 933 (33\%) students from grade three.

Due to the COVID-19 pandemic, communication between researchers and students is limited to online. The questionnaire survey method can be carried out in online platforms, which is convenient to use and low in cost. Moreover, the data results obtained are highly standardized, quantitative and scientific, etc., and the questionnaire survey method is increasingly widely used (Xu \& Li, 2015). The Wenjuanxing, a popular online survey platform in China, has rich functions, easy to edit and has perfect data output function (Zhang \& Zhang, 2011).

\subsection{The design of questionnaire}

First, we proposed the topic of the questionnaire survey, listed several dimensions of the topic, and described the corresponding question items. Second, three experts from educational technology were consulted about the dimensions and question items, and they put forward suggestions to improve them. According to these suggestions, we retained the commonly agreed dimensions and items, deleted the disagreed parts, and sought advices from other experts on controversial issues. Third, experts have been asked for opinions on the revised dimensions and items many times until they are consistent about these. Finally, the dimensions of the questionnaire and each item were determined. This research questionnaire mainly includes the basic information of students, online live broadcast teaching, completion of homework, feedback from teacher reviews, after-school tutoring, which consist of single-choice, multiple-choice, essay questions and five-level Likert scale questions (Roberts et al., 2018). Finally, after expert evaluation and modification, a total of 41 questions were determined in the survey questionnaire, including 9 questions about basic information of students, 13 questions about online live broadcast teaching, 7 questions about completion of homework, 5 questions about feedback from teacher 


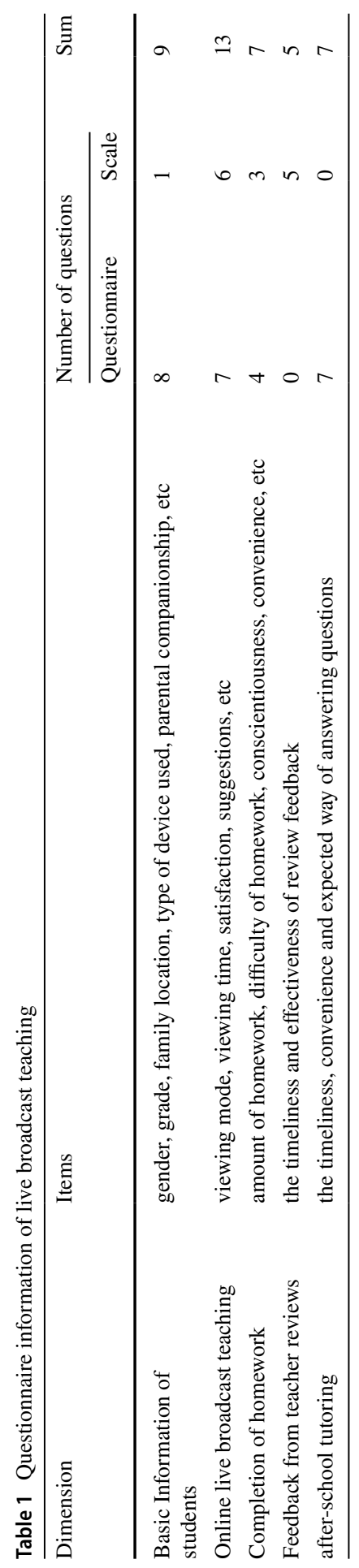


reviews, and 7 questions about after-class tutoring. The questionnaire information of live broadcast teaching is shown in Table 1.

\section{Results and discussion}

\subsection{Reliability and validity}

The one-week questionnaire is sent to the students online in the form of a link by the head teacher who is responsible for supervising the students to complete the questionnaire carefully. A total of 2828 questionnaires were collected. Before data analysis, the reliability and validity of the questionnaire should be tested. Only on the premise of ensuring the reliability and validity of the questionnaire, can data analysis be meaningful (Zeng et al., 2017). The reliability test of the questionnaire was completed by SPSS statistical software, as follows.

Reliability refers to the dependability, stability and consistency of the results measured by the scale (Wang et al., 2013). The reliability test methods mainly include Alpha coefficient method, split-half method, retest reliability method, etc. The questionnaire reliability test uses Alpha coefficient method. According to relevant literature, when Cronbach's alpha is greater than 0.9, the questionnaire reliability is the best. A score around 0.8 is very good, while a score above 0.6 is good (Ma et al., 2015; Pan, 2019). All dimensions' Cronbach's alpha of this questionnaire ranged from 0.643 to 0.866 , and the overall value was 0.841 , indicating good reliability, as shown in Table 2.

Validity refers to content validity in this study. The questionnaire items have been revised and improved after multiple rounds of three experts' consultation, and the validity of the content can be guaranteed.

\subsection{Descriptive statistics}

\subsubsection{Course satisfaction}

Course satisfaction includes three aspects: course content, teacher-student communication, and teacher's teaching enthusiasm. The content of the course refers to the degree to which students have mastered the content of learning, and the resulting sense of accomplishment. Teacher-student communication is the experience of teachers' explanations, incentives and various interactive activities in the teaching

Table 2 Cronbach's alpha for each dimension and the whole

\begin{tabular}{llllll}
\hline & $\begin{array}{l}\text { Basic Informa- } \\
\text { tion of students }\end{array}$ & $\begin{array}{l}\text { Online live } \\
\text { broadcast teach- } \\
\text { ing }\end{array}$ & $\begin{array}{l}\text { Completion of } \\
\text { homework }\end{array}$ & $\begin{array}{l}\text { Feedback from } \\
\text { teacher reviews }\end{array}$ & whole \\
\hline $\begin{array}{l}\text { The number of items } \\
\text { Alpha value }\end{array}$ & 1 & 6 & 3 & 5 & 15 \\
\hline
\end{tabular}


Table 3 Live broadcasting teaching satisfaction $(\mathrm{n}=2828)$

\begin{tabular}{|c|c|c|c|c|c|c|c|c|c|c|}
\hline \multirow[t]{2}{*}{ Items } & \multicolumn{2}{|c|}{ Very satisfied } & \multicolumn{2}{|c|}{$\begin{array}{l}\text { Somewhat } \\
\text { satisfied }\end{array}$} & \multicolumn{2}{|c|}{$\begin{array}{l}\text { Neither } \\
\text { satisfied nor } \\
\text { dissatisfied }\end{array}$} & \multicolumn{2}{|c|}{$\begin{array}{l}\text { Somewhat } \\
\text { dissatisfied }\end{array}$} & \multicolumn{2}{|c|}{$\begin{array}{l}\text { Very dis- } \\
\text { satisfied }\end{array}$} \\
\hline & $\mathrm{n}$ & $\%$ & $\mathrm{n}$ & $\%$ & $\mathrm{n}$ & $\%$ & $\mathrm{n}$ & $\%$ & $\mathrm{n}$ & $\%$ \\
\hline \multicolumn{11}{|l|}{ Course } \\
\hline Content & 1280 & 45.26 & 895 & 31.65 & 563 & 19.91 & 76 & 2.69 & 14 & 0.5 \\
\hline Communication & 1448 & 51.2 & 868 & 30.69 & 456 & 16.12 & 43 & 1.52 & 13 & 0.46 \\
\hline Teachers' enthusiasm & 1414 & 50 & 791 & 27.97 & 540 & 19.09 & 70 & 2.48 & 13 & 0.46 \\
\hline \multicolumn{11}{|l|}{ Homework } \\
\hline Completion & 1400 & 49.5 & 1158 & 40.95 & 208 & 7.36 & 30 & 1.06 & 32 & 1.13 \\
\hline Submission & 724 & 25.6 & 718 & 25.39 & 1229 & 43.46 & 133 & 4.7 & 24 & 0.85 \\
\hline Teachers' feedback & 1325 & 46.85 & 1153 & 40.77 & 286 & 10.11 & 13 & 0.46 & 51 & 1.8 \\
\hline Answering questions & 831 & 29.38 & 1395 & 49.33 & 544 & 19.24 & 23 & 0.81 & 35 & 1.24 \\
\hline
\end{tabular}

process. Teaching enthusiasm means that students feel the teacher's devotion to the teaching work. As shown in Table 3, most students are satisfied with live broadcast teaching. More than $50 \%$ of students are very satisfied with course communication and teachers' enthusiasm. Nearly $80 \%$ of students are somewhat or very satisfied with course content. Therefore, most students are satisfied with the live broadcast teaching in class, which is similar to the other research results (Cui, 2018).

\subsubsection{Homework satisfaction}

Homework satisfaction includes two aspects: homework completion and homework submission. The completion of homework refers to the completion of the homework on time according to the teacher's requirements and the accuracy rate is above $80 \%$. Assignment submission is the convenience of using the Learning Management System (LMS) when students submit their assignments. As shown in Table 3, nearly $50 \%$ of students are very satisfied with the completion of the course. However, only $25.6 \%$ of students are very satisfied with course submission. This means that students are not too satisfied with the operation of LMS. There may be two reasons for this. First, during the COVID-19 pandemic, students use less LMS and are unfamiliar with its operation, making it inconvenient to use. Secondly, due to the rapid increase in the number of users, LMS's customer service did not provide adequate support for students. Students encountered problems in the process of using LMS and could not get timely answers.

\subsubsection{Teacher's feedback satisfaction}

Table 3 shows that $46.85 \%$ of students were very satisfied with teachers' feedback. Only a few students are somewhat or very dissatisfied with teacher's feedback. Most students always get the teacher's feedback on their homework in time. Most students think that the teacher's feedback is helpful or very helpful to their study, and a few 
students think that the teacher's feedback is not helpful at all. In the live broadcast teaching model, students submit their homework online to teachers for review and feedback. The online method also enables teachers to review students' homework without time and space constraints, at the same time they have more time and energy to feedback students' homework during the live broadcast teaching. Therefore, students in the live broadcast teaching model have high satisfaction with teachers' review and feedback.

\subsubsection{Satisfaction with answering questions}

As shown in Table 3, nearly $49.33 \%$ of students were only somewhat satisfied with answering questions. This means that students are not too satisfied with answering questions. The reason lies in two aspects: one is that teachers have rarely participated in online Q\&A activities in the past and are not good at this way of communication. At the same time, they are not proficient in the operation of the Q\&A system, which makes the Q\&A effect not good enough. On the other hand, teachers have heavy teaching tasks, and answering questions requires extra leisure time, and the response to students is not timely, which affects students' satisfaction with answering questions.

\subsection{Differences analysis}

\subsubsection{Gender}

In order to understand the differences of learning time, course satisfaction, learning consciousness and other relevant dimensions of students of different genders in the process of live teaching, the independent sample test was used to compare and analyze the variables of different genders in each dimension. The analysis results showed that there were significant differences $(\mathrm{P}<0.05)$ between male and female students in the following three aspects: the duration of watching the live broadcast in the dimension of online live broadcast teaching, the duration of completing the homework in the dimension of offline independent completion of homework with both quality and quantity guaranteed, and the dimension of teachers' evaluation and feedback. And there is no significant difference between the online live teaching teachers' course satisfaction and the offline convenience of completing and submitting homework independently $(\mathrm{P}>0.05)$. The results also reveal that $95.28 \%$ of the female students and $92.16 \%$ of the male students watched the whole broadcast according to the class schedule. In terms of the completion of assignments on time with both quality and quantity guaranteed, $55.69 \%$ of girls and $43.97 \%$ of boys choose "always true". The proportion of girls who always read teachers' feedback carefully is still higher than that of boys. The results also show that the conscientiousness of female students is higher than that of male students, which is consistent with teachers' interview in which most teachers believe that female students are more self-disciplined and learn more carefully than male students in the process of 
live teaching. This is also similar to the research results of Chen et al. (2011) that female middle school students have a higher degree of learning engagement than male students, which may be the reason for the significant difference in whether teacher feedback is helpful in the dimension of teacher review feedback.

\subsubsection{Grade}

In order to understand the differences in learning time, course satisfaction, learning consciousness and other relevant dimensions of students of different grades in the process of live teaching, one-way analysis of variance was used to compare and analyze the variables of different grades in each dimension. The results showed that there were significant differences in students' grades in the following three aspects: the teaching satisfaction of teachers in the dimension of online live broadcast teaching, the convenience of submitting assignments offline and completing assignments on time with quality and quantity guaranteed and the careful checking of teachers' homework feedback in the dimension of teachers' evaluation feedback $(\mathrm{P}<0.05)$. And there was no significant difference in other aspects $(\mathrm{P}>0.05)$. Through grouping independent sample test, it was found that there was no significant difference between Grade 1 and Grade 2 in all aspects, with Grade 3 being the main difference between Grade 3 and other grades. At the same time, statistics showed that the proportion of "highly satisfied" in the lower grades was higher than that in the higher grades. The reason may be that the third grade is currently in the review stage, with deeper learning content, greater learning intensity, more learning capacity and basic knowledge already learned, so it sounds lack of passion in class. More complex content, form and capacity reduce the convenience of submitting assignments and increase the time for completing assignments. As a result, students are less likely to see teacher' feedback due to time constraints and familiarity with the content.

\subsubsection{Home location}

In order to understand the differences in learning time, course satisfaction, learning consciousness and other relevant dimensions of students from different home locations in the process of live teaching, the independent sample test was used to compare and analyze the variables in each dimension. The analysis results showed that there were significant differences $(\mathrm{P}<0.05)$ between students' home location and the following three aspects: the duration of watching live broadcast on the online live broadcast teaching dimension; the convenience to submit and finish homework on time and with quality and quantity guaranteed for the offline independent completion dimension; and the careful checking of teachers' homework feedback on the evaluation and feedback dimension. And there was no significant difference in other aspects $(\mathrm{P}>0.05)$. According to statistics, urban students are more serious in class than rural students, which is similar to the research results of Luo (2012), which shows that the learning involvement of rural junior middle school students is significantly lower than that of urban junior middle school 
students. Through interviews with teachers, it is found that, on the one hand, the hardware conditions in rural areas are worse than those in urban areas; on the other hand, there are differences between rural and urban parents in the supervision of their children, and urban parents pay more attention to their children's study than rural parents.

\subsubsection{Type of device used}

In order to understand the differences in learning time, course satisfaction, learning consciousness and other relevant dimensions of students of different types of device in the process of live teaching, one-way analysis of variance was used to compare and analyze the variables of different terminals in each dimension. The analysis results showed that there were significant differences $(\mathrm{P}<0.05)$ between students' type of device and the following three aspects: the duration of watching live broadcast on the online live broadcast teaching dimension; the duration of completing the homework in the dimension of offline independent completion of homework with both quality and quantity guaranteed; and the careful checking of teachers' homework feedback on the evaluation and feedback dimension. And there was no significant difference in other aspects $(\mathrm{P}>0.05)$. Through statistics, it is found that the proportion of tablets is slightly higher than that of computers in terms of whether teachers' feedback can be obtained in time, and the proportion of computers is the highest in other aspects, indicating that the use of computer terminals for live teaching is better than other terminals. The reason may be that the computer screen is bigger than the mobile phone, and the visual effect is better when watching the teacher's live teaching. Although mobile phones are not limited by space, they are easily affected by external factors such as playing games and answering calls. In addition, it is easier for parents to supervise the live broadcast by using a computer, and the computer is more convenient to control by using a mouse than a mobile phone.

\subsubsection{Parental companionship}

In order to understand the differences in learning time, course satisfaction, learning consciousness and other relevant dimensions of parental companionship in the

Table 4 Statistics on parental companionship and students' online live satisfaction $(n=2828)$

\begin{tabular}{|c|c|c|c|c|c|c|c|c|c|c|c|}
\hline \multirow[t]{2}{*}{$\begin{array}{l}\text { Parental com- } \\
\text { panionship }\end{array}$} & \multicolumn{2}{|c|}{ Very satisfied } & \multicolumn{2}{|c|}{$\begin{array}{l}\text { Somewhat } \\
\text { satisfied }\end{array}$} & \multicolumn{2}{|c|}{$\begin{array}{l}\text { Neither satisfied } \\
\text { nor dissatisfied }\end{array}$} & \multicolumn{2}{|c|}{$\begin{array}{l}\text { Somewhat } \\
\text { dissatisfied }\end{array}$} & \multicolumn{2}{|c|}{$\begin{array}{l}\text { Very dis- } \\
\text { satisfied }\end{array}$} & \multirow[t]{2}{*}{ sum } \\
\hline & $\mathrm{n}$ & $\%$ & $\mathrm{n}$ & $\%$ & $\mathrm{n}$ & $\%$ & $\mathrm{n}$ & $\%$ & $\mathrm{n}$ & $\%$ & \\
\hline never & 85 & 39.91 & 60 & 28.17 & 54 & 25.35 & 10 & 4.69 & 4 & 1.88 & 213 \\
\hline seldom & 235 & 36.66 & 233 & 36.35 & 145 & 22.62 & 24 & 3.74 & 4 & 0.62 & 641 \\
\hline sometimes & 311 & 41.03 & 265 & 34.96 & 162 & 21.37 & 15 & 1.98 & 5 & 0.66 & 758 \\
\hline often & 398 & 47.66 & 258 & 30.90 & 160 & 19.16 & 19 & 2.28 & 0 & 0.00 & 835 \\
\hline always & 251 & 65.88 & 79 & 20.73 & 42 & 11.02 & 8 & 2.10 & 1 & 0.26 & 381 \\
\hline
\end{tabular}


process of live teaching, one-way analysis of variance was used to compare and analyze the variables of parental companionship in each dimension. The analysis results showed that there were significant differences in all aspects of parental companionship $(\mathrm{P}<0.05)$, and statistics showed that the more parental companionship, the students done better. For example, course satisfaction, as shown in Table 4, the proportion of parental accompany in different course satisfaction is shown from left to right. The results revealed that the more parents accompany the students, the more the students are satisfied with the course. Other research also showed that the more parents' participation in children's learning, the better their children's learning performance will be (Gao, 2016; Li, 2019). The self-control of middle school students is not as good as that of adults, and they tend to be distracted when participating in online learning. Parents' companionship can give students emotional support, and may help to achieve the learning tasks smoothly, thereby improving course satisfaction.

\section{Implications}

\subsection{Using tools to increase interaction in class}

In essay questions, many students put forward the problems of lack of interaction, and they were unable to ask questions and send text in class activities. The class is dominated by teachers' activities, students' participation is not high, and students' problems cannot be found and solved in time. Students are only simple knowledge receivers in the live broadcast, which is prone to problems such as inattention, boredom and so on. Relevant studies have shown that the appropriate application of information communication technology increases interaction, and students will be more actively involved in learning activities (Chang \& Sperling, 2014; Tian, 2018). Teachers and students cannot have explicit interaction in class, so they can be divided into grades and disciplines to establish a listening group, which is consisted of teacher and students for a course (eg. mathethetics), so that teacher can appropriately add interactive links in class, such as adding Q\&A links, teachers ask questions, students think and send the thinking results to the group, and teachers can give targeted comments. In the process of class, any problems can be sent to the group, and the teacher can check it at any time so as to find out the students' learning problems and solve them in class in time. If conditions permit, group videos can also be conducted, so that teachers can see students' learning manner, earnest or perfunctory, doubt or mastery, to help teachers control the teaching rhythm more effectively through students' classroom behavior.

\subsection{Give time to strengthen thinking in class}

The answers for essay questions also revealed teachers have such a fast pace in class that students may not be able to keep up with the pace, organize notes, and lack time to think. They hope teachers can slow down, especially in difficult places. Some 
students even suggested that the pace of class could be adjusted by appropriately increasing the class time. If the teaching speed is too fast, students will not be able to keep up with the pace, especially if the knowledge point is strongly consistent, students will be "left behind", so that students will not have the motivation to continue to listen carefully, which will affect the quality of live teaching. Therefore, in the process of live broadcasting teaching, teachers should take into full consideration factors such as network fluency, response time, student acceptance, and thinking time, etc., and appropriately slow down the teaching speed and give students appropriate time to think and take notes, so that students will not be affected by lack of time to think and take notes in class. It is important to ensure that students have time to think and record and achieve high-quality learning, which further enhance students' sense of participation and satisfaction.

\subsection{Strengthen after class supervision with peers}

For homework completion, the results showed that the students' self-consciousness is not high. Only $49.5 \%$ of the students always complete the teacher's assignment with good quality on time while there is $9.55 \%$ of the students rarely do that. Only $50.18 \%$ of the students are able to finish the homework without any supervision from teachers and parents, and boys' self-consciousness is lower than that of girls'. These data shows that students' self-consciousness of completing homework needs to be improved in the process of live teaching. As an extension of classroom teaching, homework is very important. It can detect students' learning in class, timely find out what students have not mastered, and make up for it. It is also conducive to cultivating students' independent learning ability and learning habits (Yu, 2019). Supervision is the guarantee of learning quality, which is extremely important in home-based learning. Ineffective or meaningless learning is sometimes more serious than the negative consequences caused by non-learning. In order to reinforce the supervision, study groups can be established to cultivate students' self-restraint, group cultural atmosphere and collaborative efficiency, so that students can supervise, encourage and praise each other, which will form the learning community as the protagonist of online teaching (Zhu et al., 2020). When setting up a group, we may consider the self-consciousness difference between boys and girls, and establish a study group with a combination of boys and girls to give full play of the advantages of girls' sense of self-consciousness and responsibility, and improve the efficiency of small work cooperation. Of course, it is also necessary to give full play to the role of parents' supervision, which plays an important role in the learning process. The result revealed that parents' accompanying with their children's learning can significantly affect students' learning engagement.

\subsection{Using the platform to answer questions after class}

The survey results show that only $34.62 \%$ of students can always solve problems in time, and $26.18 \%$ can rarely solve problems in time. Moreover, $59.51 \%$ of students hold that there are more problems in live teaching than in traditional learning. 
However, the separation of time and space between teachers and students in live teaching model has brought certain learning difficulties for learners. Therefore, providing good counseling and help for learners is an important part of live teaching (Zhang \& Zhang, 2010). Compared with mobile terminals, students learn better through computer terminals. Therefore, online teaching design should consider the characteristics of computer terminals and optimize the interface of courses. Relevant research shows that the Q\&A forum is favorable for the majority of teachers and students because of its flexibility in time and space (Sun \& Jian, 2007). Therefore, we may set up some online Q\&A forum by grade and subject, such as Post bar, DingTalk group, etc. After students ask questions, the subject teacher answers them, so that students can check the questions and answers at any time. A teacher does not need to answer the same question repeatedly, and more questions can also be answered by more teachers, which increases the timeliness and convenience of students' problem solving.

\section{Conclusions}

Taking a middle school in the west part of China as an example, this study conducted an online survey to investigate live broadcast teaching during the COVID-19 pandemic. The independent sample test and one-way analysis of variance were used to statistically analyze the differences among the students' genders, grades, home location, type of device used and parental companionship.

Nevertheless, this study has some limitations that should be addressed in future research. Firstly, the data in this study comes from a middle school from the western part of China, which is difficult to generalized to other schools. Future studies can sample different schools and conduct large-scale surveys, making the conclusions are more generalizable. Secondly, the survey population only focused on students, lacking data from teachers, school administrators and parents, and the analysis of teaching was not comprehensive enough. Future studies can add the above population with wider horizon, making the research more deeply. Finally, the research method is slightly simpler, only using questionnaires, and they are all self-reporting. Future research can involve observations, and get more in-depth understanding about the topic.

Funding This work was supported by the Humanities and Social Sciences of Ministry of Education Plan foundation [grant number 19XJA880011]; Higher Education Teaching Reform Project of Chongqing [grant number 202051]; The Continued Education Research Project of Southwest University [grant number SWU2008022]. 


\section{References}

Bai, H. Q. (2013). Research on the influencing Factors of virtual learning communities used by primary and secondary school teachers. E-Education Research, 34(11), 46-52.

Chang, Y., \& Sperling, M. (2014). Discourse and identity among ESL learners: A case study of a community college ESL classroom. Research in the Teaching of English, 49(1), 31-51.

Chen, G. H., Feng, D. G., \& Liu, Z. H. (2011). A Study on the correlation between learning Engagement of middle school students and school psychological atmosphere. Chinese Journal of School Doctor, 25(04), 244-246.

Chen, N. S., Ko, H. C., \& Kinshuk, \& Lin, T. (2005). A model for synchronous learning using the Internet. Innovations in Education and Teaching International, 42(2), 181-194.

Cheng, X. J., Pi, Z. L., \& Hong, J. Z. (2020). The Influence of live broadcasting model on the teaching effect -Taking the course "career planning" as an example. Modern Educational Technology, 30(2), 85-90.

Cui, X. L. (2018). Research and reflection on the application of remote live teaching in senior high school chemistry teaching-Take the No.1 Middle School of Shilin Yi Autonomous County as an example. Master, Yunnan Normal University.

Gao, L. (2016). How parent involvement, parents' autonomy support, teacher support affect students' homework effort: the self-determination perspective. Central China Normal University.

Halverson, L. R., Graham, C. R., Spring, K. J., Drysdale, J. S., \& Henrie, C. R. (2014). A thematic analysis of the most highly cited scholarship in the first decade of blended learning research. The Internet and Higher Education, 20, 20-34. https://doi.org/10.1016/j.iheduc.2013.09.004

Hui, D. S., Azhar, I. E., Madani, T. A., et al. (2020). The continuing 2019-nCoV epidemic threat of novel coronaviruses to global health - The latest 2019 novel coronavirus outbreak in Wuhan. China. International Journal of Infection Disease 91, 264-266.

Kuo, Y. C., Walker, A., Belland, B., Schroder, K. \& Kuo, Y. T. (2014). A Case Study of Integrating Interwise: Interaction, Internet Self-Efficacy, and Satisfaction in Synchronous Online Learning Environments. International Review of Research in Open and Distributed Learning, 15 (1), 161-181. https://doi.org/10.19173/irrodl.v15i1.1664

Li, C., \& Xin, L. (2008). Research on the evaluation methods of questionnaire reliability and validity. Chinese Journal of Health Statistics, 25(05), 541-544.

Li, C. X. (2019). The effect of parent participation on middle school students' learning performancebased on China Education Panel Survey Data (CEPS). Central China Normal University.

Liu, J. (2017). "Live plus education": A new form of "Internet Plus" learning and its value inquiry. Journal of Distance Education, 35(1), 52-59.

Luo, L.S. (2012). Study on the relationship between personality characteristics, learning engagement and social support of junior high school students. Abstracts of the 15th National Academic Congress of Psychology, 243.

Ma, R., Wu, X. X., \& Sun, Q. J. (2015). Construction of evaluation index system about the communication effect of MOOC. Modern Educational Technology, 25(06), 71-77.

Martin, F., Ahlgrim-Delzell, L., \& Budhrani, K. (2017). Systematic review of two decades (1995 to 2014) of research on synchronous online learning. American Journal of Distance Education, 31(1), 3-19.

Ministry of Education, PRC. (2020). Notice by the Leading Party Group of the Ministry of Education of the Communist Party of China on Coordinating COVID-19 Epidemic Prevention and Control and education Reform and Development in the education system. http://www.moe.gov.cn/srcsite/A17/ s7059/202002/t20200228_425499.html 2020-02-28.

Ministry of Education, PRC. (2020). Notice of the Ministry of Education on the extension of the spring Semester in 2020. http://www.moe.gov.cn/jyb_xwfb/gzdt_gzdt/s5987/202001/t20200127_416672. html,2020-01-27

Moridani, M. (2007). Asynchronous video streaming vs. synchronous videoconferencing for teaching a pharmacogenetic pharmacotherapy course. American Journal of Pharmaceutical Education, 71(1), 1-10.

Murphy, E., \& Laferriere, T. (2007). Adopting tools for online synchronous communication: Issues and strategies. In Making the transition to E-learning: Strategies and issues (pp. 318-334). IGI Global.

Ng, K. C. (2007). Replacing Face-to-Face Tutorials by Synchronous Online Technologies: Challenges and pedagogical implications. The International Review of Research in Open and Distributed Learning, 8(1). https://doi.org/10.19173/irrodl.v8i1.335 
Pan, L.F. (2019). The current state, problems and countermeasures of ICT-supported teacher learning. e-Education Research, 40(08),108-115.

Park, Y. J., \& Bonk, C. J. (2007). Is online life a breeze? A case study for promoting synchronous learning in a blended graduate course. MERLOT Journal of Online Learning and Teaching, 3(3), 307-323.

Richardson, K. (2020). Online tools with synchronous learning environments. In Handbook of Research on Online Pedagogical Models for Mathematics Teacher Education (pp. 68-78). IGI Global.

Roberts, K., Hankinson, A., Swanson, I., \& (Yonnie) Chyung, S. Y. . (2018). Determine usage of a midpoint in the likert scale. Training, 3, 14 .

Salmon, G. (2000). E-moderating: The key to teaching and learning online. Kogan Page.

Sun, S. Y., \& Jian, G. B. (2007). Research on influencing factors of online counseling Q\&A. China Educational Technology, 10, 39-43.

Teng, D. C. E., Chen, N. S., \& Leo, T. (2012). Exploring students' learning experience in an international online research seminar in the Synchronous Cyber Classroom. Computers \& Education, 58(3), 918-930.

Tian, S. (2018). The construction and empirical study of open discourse classroom environment. Modern Distance Education Research, 03, 104-112.

Wang, X. L., Lin, S., Chen, L. Y. (2013). Research on factors influencing the willingness to use e-learning platform under mixed Learning model. e-Education Research, 34(11),72-78, 85.

$\mathrm{Xu}$, J. H., \& Li, Y. (2015). The analysis of the questionnaire survey articles of library science journals in 2014. Library \& Information, 06, 92-96.

Yu, J. X. (2019). Strategies to improve the effectiveness of high school English homework. Education Modernization, 6(47), 272-273.

Zeng, T. S., Zhu, X. Y., Wan, X. (2017). Investigation and improvement countermeasures on current situation of ICT in education in compulsory education schools in poverty-stricken areas: A case study of western Yunnan Area. e-Education Research, 38(10),51-56.

Zhang, D., \& Zhang, X. H. (2010). Analysis of the effectiveness of online teaching resources-Illustrate by the curriculum of counseling Q \& A library. Modern Distance Education, 4, 42-45.

Zhang, K, Zhang, B.Y. (2011). Functions of mainstream online surveys platform in China. Library \& Information, (05),78-80、100.

Zhu, Z. T., Guo, S. Q., Di, D., \& Liu, S. N. Y. (2020). The policy interpretation, key issues and countermeasures of "Suspension of classes without suspension." China Educational Technology, 4, 1-7.

Publisher's Note Springer Nature remains neutral with regard to jurisdictional claims in published maps and institutional affiliations. 